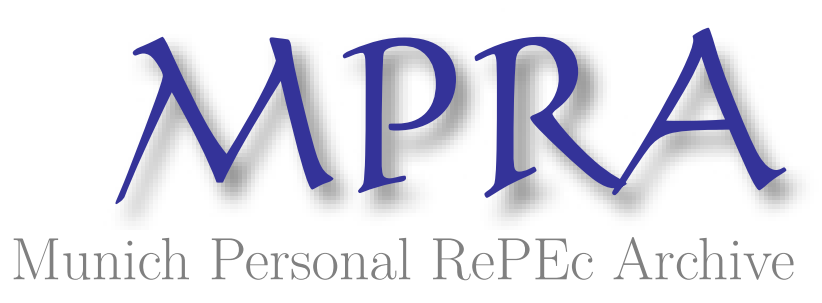

\title{
Understanding the Backus-Smith Puzzle: It's the (Nominal) Exchange Rate, Stupid
}

Hess, Gregory and Shin, Kwanho

February 2006

Online at https://mpra.ub.uni-muenchen.de/696/

MPRA Paper No. 696, posted 07 Nov 2006 UTC 


\title{
Understanding the Backus-Smith Puzzle: It's the (Nominal) Exchange Rate, Stupid
}

\author{
Gregory D. Hess \\ Claremont McKenna College and CESifo
}

Kwanho Shin

Korea University and ISER

February 2006 


\begin{abstract}
Backus, Kehoe and Kydland (BKK 1992) showed that if international capital markets are complete, consumption growth correlations across countries should be higher than their corresponding output growth correlations. In stark contrast to the theory, however, in actual data the consumption growth correlation is lower than the output growth correlation. By assuming trade imperfections due to non-traded goods, Backus and Smith (1993) showed that there is an additional impediment that works to lower the consumption growth correlation. While Backus and Smith's argument was successful in partially explaining the low growth correlation puzzle, it contributed to generating another puzzle because the data forcefully showed that consumption growth is negatively correlated with the real exchange rate, which is a violation of the theory. In this paper, by decomposing the real exchange rate growth of the OECD countries into the nominal exchange rate growth and the inflation differential, we find that nominal exchange rate movements are the main source for the Backus-Smith puzzle. We find that the nominal exchange rate moves counter-cyclically with consumption movements, which is a violation of the risk sharing theory with non-traded goods. We also find that the violations are more pronounced when nominal exchange rate changes are larger in absolute value. In contrast, the negative of bilateral inflation differentials is positively correlated with bilateral consumption movements. The latter finding is in accordance with the theory. Furthermore, using intranational data for the United States where the nominal exchange rate is constant, the Backus-Smith puzzle disappears, although complete risk sharing is rejected.
\end{abstract}

JEL Codes: F31, F36, F37, E21, E32, E41, E44

Keywords: Risk Sharing, Exchange Rate 


\section{Introduction}

An important issue in international economics is to measure the extent to which international financial markets improve economic welfare by offering opportunities to share risk across countries. An influential paper by Backus, Kehoe and Kydland (BKK 1992) showed that if international capital markets are complete, country-specific technology shocks lead to equilibrium consumption paths that are both less variable and less closely related to domestic output than they are in closed economy real business cycle models. While quantitative properties of the theoretical economy depend to a large extent on the specification and the parameter values of the model, the theory suggests that the consumption growth correlation across countries should be higher than output growth correlation.

In stark contrast to the theory, however, BKK found using data for 11 OECD economies that the consumption growth correlation is actually lower than the output growth correlation. This is referred to as one of the six major puzzles in international economics and termed as international consumption correlation puzzle by Obstfeld and Rogoff (2001). ${ }^{1}$ Since then there have been various attempts made to solve the puzzle, but none has been thoroughly convincing. An important attempt, for example, is to introduce trade costs that represent transport costs and other costs such as tariffs and other non-tariff barriers. ${ }^{2}$ Backus and Smith (1993), by introducing non-traded goods in the canonical model, demonstrate that there is another wedge that works to lower consumption growth correlation: namely, when

\footnotetext{
${ }^{1}$ Backus, Kehoe and Kydland (1992) initially called this as "quantity anomaly," coupled with "price anomaly" pointed out in the same paper. Recently Crucini (1999), Hess and Shin (2000) and Del Negro (2002) extended the analysis to intranational data based on state level regional data in the U.S. and found that the puzzle is preserved even within a country.

${ }^{2}$ Recently Obstfeld and Rogoff (2001) argue that by explicitly introducing trade costs of international trade, one can go far toward explaining a great number of main empirical puzzles in international economics. For the criticism of their view see also Engel (2001).
} 
real exchange rates are not constant, even complete risk sharing does not necessarily call for perfectly synchronous movements in consumption growth. ${ }^{3}$ Rather, they demonstrate that consumption growth is higher for countries that experience relative drops in the real price of consumption because risk sharing implies that transfers should be made to countries that can exploit lower prices.

While Backus and Smith's theory was successful in lowering the theoretically predicted consumption growth correlation across countries, it contributed to generating another puzzle because the data forcefully show that consumption growth co-moves with the real exchange rate in the direction opposite to that predicted by theory. ${ }^{4}$ In this paper, by decomposing the real exchange rate growth for OECD countries into nominal exchange rate growth and the inflation differential, we shed new light on the Backus and Smith puzzle. We find that nominal exchange rates move counter-cyclically with consumption movements, contributing to a violation of the basic risk sharing theory with non-traded goods. However, the negative of the bilateral inflation differentials is positively correlated with bilateral consumption movements. Such a correlation indicates that if the nominal exchange rate did not fluctuate, the movements of bilateral inflation alone could ensure the real exchange rate to be positively correlated to bilateral consumption growth. In other words, the Backus-Smith puzzle is mainly due to the atheoretical behavior of the nominal exchange rate.

To further confirm that the nominal exchange rate fluctuations contribute to the Backus-Smith puzzle, we perform three experiments. First, we divide the sample into two cases: one with large exchange rate changes and the other with small exchange rate changes.

\footnotetext{
${ }^{3}$ The importance of real exchange rate fluctuations on consumption risk sharing condition was initially pointed out by Obstfeld (1989) and further analyzed in Kollman (1995).

${ }^{4}$ Ravn (2001) shows that variation of the utility function does not resolve the Backus and Smith puzzle. In particular despite introducing non-separabilities in the utility function including effects of money balances, leisure, government spending, and habit persistence, the puzzle remains data of OECD countries.
} 
We find that the atheoretical behavior of the real exchange rate is present primarily when nominal exchange changes are large. ${ }^{5}$ When nominal exchange changes are small, movements of the nominal exchange rate as well as those of bilateral inflation differentials are consistent with the theory. Overall our findings indicate that large changes in the nominal exchange rate make it difficult for consumption dynamics to conform to the theory.

Second, we attempt to examine if the Backus-Smith puzzle is due to existence of incomplete risk sharing. We modify the model so that only portion of income risk is shared across countries. The remaining portion is assumed not to be shared. In this simple setting, we find mixed evidence: the Backus-Smith puzzle becomes less severe in the sense that the real exchange rate is no longer countercyclical. However we continue to fail to find statistically significant procyclical movements of the real exchange rate. When we decompose the real exchange rate, even in the case of partial risk sharing, we find that the nominal exchange rate is the major culprit that prevents the real exchange rate from being procyclical.

Third, in order to better understand the role of the nominal exchange rate, we follow recent studies and re-examine the same issues across U.S. economic regions in the same country. So-called intranational evidence provides a natural experiment for understanding international puzzles since regions in the same country share the common currency and hence the nominal exchange rate, though not the real one, is always equal to one. In this case fluctuations of the real exchange rate are solely due to inflation differentials. Based on data for 50 U.S. states, we find that while risk sharing is still somewhat limited, movements of the real exchange rate are consistent with the risk sharing theory. This also confirms that the existence of nominal exchange rate variation is mainly responsible for the existence of

\footnotetext{
${ }^{5}$ In this case, movements of bilateral inflation differentials as well as those of the nominal exchange rate are inconsistent with the theory
} 
the Backus-Smith puzzle.

The rest of the paper is organized as follows. In Section 2, the model is briefly introduced. Section 3 reports the empirical analysis and Section 4 concludes.

\section{The Model}

We start by deriving the equations that well be empirically investigated in the next section. The theory is based on a simple set-up that is similar to Backus and Smith (1993). Consider an endowment economy which consists of $N$ countries indexed by $i=1, \ldots, N .{ }^{6}$ Common information at time $t$ is represented by state $z^{t}$ that occurs with probability $\pi\left(z^{t}\right) \in[0,1]$ with $\sum_{z^{t}} \pi\left(z^{t}\right)=1$ for all $t$. In each state the economy has $N+1$ goods, a single traded good and $N$ non-traded goods associated with $N$ countries.

Each country is inhabited by an infinitely lived, representative household whose preferences are represented by the expected lifetime utility expressed as:

$$
\sum_{t=0}^{\infty} \beta^{t} \sum_{z^{t}} \pi\left(z^{t}\right) U\left(C_{i t}\left(z^{t}\right), X_{i t}\left(z^{t}\right)\right)
$$

where $C_{i t}\left(z^{t}\right)$ denotes consumption in the $i^{\text {th }}$ country at time $t$, consisting of a composite good made of the single traded good, $C_{i t}^{T}\left(z^{t}\right)$ and the non-traded good, $C_{i t}^{N}\left(z^{t}\right), X_{i t}$ denotes all non-consumption components including preference shocks that affect utility and $0<\beta<1$ is the subjective discount factor that is assumed to be the same across countries. We assume that while traded goods are traded without costs, non-traded goods incur the infinite amount of costs to trade. We denote the composite good by $C_{i t}=C\left(C_{i t}^{T}, C_{i t}^{N}\right)$ and its price in the local currency by $P_{i t}$. We also assume that $U$ is common to all countries, with the typical

\footnotetext{
${ }^{6}$ The assumption of an endowment economy is made solely for expositional simplicity; the main results of the analysis are unchanged even if we model a production economy.
} 
regularity conditions. ${ }^{7}$ In a number of models in the literature that test international risk sharing, it is common to assume that there is a single traded good that is consumed by all countries. In a such a world, if prices are perfectly flexible, the bilateral real exchange rate is equal to one all the time. However, a recent strand in the international economics literature stresses the importance of heterogeneity of goods and stickiness of local prices. One important implication of these changes is that the real exchange rate is no longer instantaneously equal to one. Following this fashion, we allow the possibility of the real exchange rate to move around, by introducing non-traded goods.

Suppose that complete contingent securities that are quoted in terms of the local currency are also traded across countries without costs. In this case, the equilibrium with complete risk sharing is made through pooling only tradable goods. In other words, the equilibrium is obtained by the solution of the social planner' problem as follows:

$$
\max \sum_{i=1}^{N} \lambda_{i} \sum_{t=0}^{\infty} \beta^{t} \sum_{z^{t}} \pi\left(z^{t}\right) U\left(C\left(C_{i t}^{T}\left(z^{t}\right), C_{i t}^{N}\left(z^{t}\right)\right), X_{i t}\left(z^{t}\right)\right)
$$

subject to the resource constraints:

$$
\begin{aligned}
\sum_{i=1}^{N} C_{i t}^{T}\left(z^{t}\right) & \leq \sum_{i=1}^{N} W_{i t}^{T}\left(z^{t}\right) \\
C_{i t}^{N}\left(z^{t}\right) & \leq W_{i t}^{N}\left(z^{t}\right)
\end{aligned}
$$

where $W_{i t}^{T}\left(z^{t}\right)$ and $W_{i t}^{N}\left(z^{t}\right)$ are endowments of the traded and non-traded goods in the $i^{t h}$ country in state $z^{t}$ at time $t$. The resource constraint (3) implies that the tradable good can be distributed freely across countries whereas the resource constraint (4) implies that the non-traded good should be consumed within country.

\footnotetext{
${ }^{7}$ Homotheticity of the utility function is sufficient for the existence of prices and the composite good such that $P_{t}^{T} C_{i t}^{T}+P_{i t}^{N} C_{i t}^{N}=P_{i t} C_{i t}$ where $P_{t}^{T}$ and $P_{i t}^{N}$ are prices of the tradable good and the non-traded good in the country $i$ in the local currency.
} 
It is straightforward to derive the optimal condition for the above problem and represent it in terms of the bilateral condition between any country pair $(i, j)$ that is satisfied in every state as follows: ${ }^{8}$ :

$$
\beta \frac{U_{c}\left(C_{j t+1}, X_{j t+1}\right)}{U_{c}\left(C_{j t}, X_{j t}\right)}=\beta \frac{\epsilon_{i j t+1}}{\epsilon_{i j t}} \frac{U_{c}\left(C_{i t+1}, X_{i t+1}\right)}{U_{c}\left(C_{i t}, X_{i t}\right)}
$$

where $\epsilon_{i j t}$ is the bilateral real exchange rate between country $i$ and $j$ (the price of the composite good in country $j$ in terms of the composite good in country $i$ ) at time $t .{ }^{9}$ If $\epsilon_{i j t}=1$ for all $t$, this condition reduces to the typical condition for international risk sharing that states that real marginal rates of substitution are equalized across countries. This condition posits that real marginal rates of substitution are different across countries as long as the real exchange rate changes.

Utilizing the definition of the real exchange rate, $\epsilon_{i j t}=e_{i j t} \frac{P_{j t}}{P_{i t}}$, where $e_{i j t}$ is the nominal exchange rate between country $i$ and $j$ (i.e., the price of country $j$ currency in terms of country $i$ currency) at time $t$, we can rearrange equation (5) as follows:

$$
\beta \frac{P_{j t}}{P_{j t+1}} \frac{U_{c}\left(C_{j t+1}, X_{j t+1}\right)}{U_{c}\left(C_{j t}, X_{j t}\right)}=\beta \frac{e_{i j t}}{e_{i j t+1}} \frac{P_{i t}}{P_{i t+1}} \frac{U_{c}\left(C_{i t+1}, X_{i t+1}\right)}{U_{c}\left(C_{i t}, X_{i t}\right)}
$$

Equation (6) states that nominal marginal rates of substitution are equalized across countries. Since the contingent securities that are traded without costs are quoted in local currencies, complete risk sharing implies that the value of nominal currencies of equal value is the same across countries.

To make it easier to empirically implement the model, suppose that the utility function is of the CRRA (constant relative risk aversion) form with a risk aversion coefficient $\sigma$

\footnotetext{
${ }^{8}$ A similar condition has been derived by, among others, Obstfeld (1989), Backus and Smith (1995), Kollmann (1995) and Raven (2001)

${ }^{9}$ From now on, to conserve on notation, we have suppressed the state $z^{t}$ in the equation.
} 
that is common across countries:

$$
U\left(C_{i t}\right)=\frac{\left(C_{i t} X_{i t}^{\gamma_{i}}\right)^{1-\sigma}}{1-\sigma}
$$

where we also assume that the preference shocks affect the utility in a multiplicative form with the elasticity parameter, $\gamma_{i}$. Then equation (5) reduces to:

$$
\beta \frac{C_{j t+1}^{-\sigma} X_{j t+1}^{\gamma_{j}(1-\sigma)}}{C_{j t}^{-\sigma} X_{j t}^{\gamma_{j}(1-\sigma)}}=\beta \frac{\epsilon_{i j t+1}}{\epsilon_{i j t}} \frac{C_{i t+1}^{-\sigma} X_{i t+1}^{\gamma_{j}(1-\sigma)}}{C_{i t}^{-\sigma} X_{i t}^{\gamma_{j}(1-\sigma)}}
$$

Taking the logarithm in both sides of equation (8), we can derive the following equation:

$$
\Delta \ln \left(C_{i t+1}\right)=\Delta \ln \left(C_{j t+1}\right)+\frac{1}{\sigma} \Delta \ln \left(\epsilon_{i j t+1}\right)+\frac{1}{\sigma}(1-\sigma)\left(\gamma_{i} \Delta \ln \left(X_{i t+1}\right)-\gamma_{j} \Delta \ln \left(X_{j t+1}\right)\right)
$$

Equation (9) demonstrates that if the real exchange rate is constant, ignoring non-consumption shocks to utility, the growth rate of consumption is equalized across countries. Most previous studies on international risk sharing have ignored the second term as well as the third term, and tested if the growth rate of consumption moves one for one across countries. Such regressions, as mentioned above, find evidence of a severe violation of theory. ${ }^{10}$ Later studies that tried to resuscitate the theory by explicitly considering the possibility of real exchange rate movements faced another anomaly. According to equation (9), the consumption growth difference between country $i$ and $j$ should be positively correlated to the real exchange rate. To the contrary, however, Backus and Kehoe (1992) find that the consumption growth difference between country $i$ and $j$ is negatively correlated to the real exchange rate in the data. This is called the Backus-Smith puzzle.

\footnotetext{
${ }^{10}$ See, for example, Obstfeld (1989), Backus and Kehoe (1992), Canova and Ravn (1996) Lewis (1996), Sorenson and Yosha (1998), Crucini (1999) and Hess and Shin (2000).
} 


\section{Empirical Evidence}

In this section, we explore the evidence of risk sharing across countries. In particular, we examine the relationship between consumption growth rates across countries and the growth of their real exchange rate. As well, we decompose the movements in the real exchange into the movements in the nominal exchange rate and the inflation differential between countries. Our analysis of data for OECD economies and for state level data in the U.S. points to the nominal exchange rate movements as a significant source of failure of the theory to match the data.

\subsection{Preliminary Analysis}

Table 1 provides a number of summary statistics of the primary data of OECD economies (1969-2000) used in our study. Each column of the table provides the mean and standard deviation (in parentheses) of a variable of interest, while each row denotes a different OECD country in our sample. At the bottom of the table, we also report the pooled average and standard deviation of the data. The variables presented in Table 1 are those that are key for our analysis: namely, per-capita consumption growth $(\Delta c)$, per-capita output growth $(\Delta y)$, CPI inflation $(\Delta p)$, nominal exchange rate growth $(\Delta e)$, and real exchange rate growth $(\Delta \epsilon) \cdot{ }^{11}$

There are a number of interesting findings presented in Table 1. First, consumption and output growth averages to approximately 2.5 percent per year, although the standard

\footnotetext{
${ }^{11}$ Henceforth, $\Delta x \equiv \log \left(x_{t}\right)-\log \left(x_{t-1}\right)$. The CPI in this paper is more accurately the "consumption deflator", derived by dividing nominal consumption by real consumption for each country and real exchange rate data are obtained by deflating the nominal exchange rate by the CPI. The results for real exchange rate data deflated by GDP deflator are qualitatively similar and hence not reported. For interested readers, see the previous version of the paper that reports both results.
} 
deviation of consumption growth is generally larger than that for output growth. ${ }^{12}$ Second, the nominal variation in prices and exchange rates is generally large relative to the variation of real magnitudes. Indeed, the wide range of inflation experiences both within and across countries is reflected in part in the wide range of exchange rate experiences both within and across countries. Finally, the mean growth in nominal and real exchange rates for each country appear unrelated.

Table 2 provides further summary statistics for the data, although this time based on bilateral data. Again, each row denotes the data for a country while the column headings provide the mnemonic for the particular data statistic. The first five columns provide the pooled standard deviation of the bilateral series and country of interest, where a " $\tilde{x}$ " indicates a bilateral series, i.e. $\Delta \tilde{x}=\Delta \log \left(x^{d}\right)-\Delta \log \left(x^{f}\right)$ where $x^{d}$ and $x^{f}$ are domestic and foreign variables respectively. The final three columns provide pooled bilateral correlations of the data series indicated: namely, $\rho(x, y)$ is a country's pooled correlation of variables $\mathrm{x}$ and $\mathrm{y}$ using its bilateral data with all other countries in the sample. Again, as in Table 1, there are a number of key features of the data that are apparent. First, consumption growth is more volatile than output growth using the bilateral data. ${ }^{13}$ Second, the volatility of nominal variables is large relative to that of real variables such as consumption and output growth. Third, bilateral inflation movements are strongly positively correlated with nominal exchange rate growth, though they are generally uncorrelated with real exchange rate growth. Finally,

\footnotetext{
${ }^{12}$ The fact that the standard deviation of consumption growth is larger than that for output growth reflects, in part, that consumption measure in this paper includes nondurable component of consumption.

${ }^{13}$ This property is closely related to the BKK puzzle. This is easily understood from the following equa$\operatorname{tion}(\mathrm{s}): \operatorname{var}\left(\Delta y_{i t}-\Delta y_{j t}\right)=\operatorname{var}\left(\Delta y_{i t}\right)+\operatorname{var}\left(\Delta y_{i t}\right)-2 \rho\left(\Delta y_{i t}, \Delta y_{i t}\right) * \sqrt{\operatorname{var}\left(\Delta y_{i t}\right)} * \sqrt{\operatorname{var}\left(\Delta y_{j t}\right)}$ (and the equivalent equation for consumption growth). Since the consumption correlation across bilateral countries is lower than that for output, the standard deviation of bilateral consumption differentials across countries should be higher than that for bilateral output differential if the standard deviation of consumption growth is not smaller than that of output growth and the correlation measures are low (i.e. less than $1 / 2$ ).
} 
real and nominal exchange rate movements are very positively correlated at the annual frequency.

The results in Table 3 provide evidence of the relationship between bilateral consumption growth and inflation and exchange rate movements, which basically summarizes the most important finding in the paper. In particular, the first column of results in the table demonstrates that, generally speaking, real exchange rates move counter-cyclically with consumption movements. In principle, this is a violation of basic risk sharing theory with non-trade goods: as pointed out by Backus and Smith (1993), which is also denoted in equation (9), whereby shocks that raise the real exchange rates should also raise bilateral consumption growth. When we decompose the real exchange rate by $\Delta \epsilon_{t}=\Delta e_{t}-\Delta \tilde{p}_{t}$, however, we notice a very important finding. In column two, the nominal exchange rates move counter-cyclically with consumption movements, contributing the violation of the basic risk sharing theory. However, the last column of the table indicates that the negative of the bilateral inflation differential is positively correlated with bilateral consumption movements. This is true not only for the global average but also for every single OECD country considered in the table. Such a correlation indicates that if the nominal exchange rate were constant, the movements of bilateral inflation alone could conform to the theory of risk sharing by leading the real exchange rate to be positively correlated to bilateral consumption growth. In other words, the evidence in Table 3 suggests that the Backus-Smith puzzle should be mainly due to the ill behavior of the nominal exchange rate.

\subsection{Empirical Analysis}

While Tables 1 through 3 provided a wide range of evidence about the properties of the data, in this section we report evidence from the estimation of theory based equations. Recall that, 
as indicated in equation (9), the equation to be estimated is:

$$
\Delta \tilde{c}_{i t}=\beta_{0}+\beta_{1} \cdot \Delta \epsilon_{i t}+\eta_{i t}
$$

where $\eta_{i t}$ includes non-consumption preference shocks and other measurement errors. ${ }^{14}$ As noted in section 2, according to the theory of complete risk sharing with traded goods only, the coefficient on $\beta_{1}$ should be zero. In other words, with complete risk sharing, there should be no predictable change in the growth of consumption across countries. In contrast, with complete risk sharing with non-traded goods, only the coefficient on $\beta_{1}$ should be positive, significant and equal to the reciprocal of the coefficient of relative risk aversion.

The results in the top panel of Table 4 begin to provide the broad set of evidence against complete international risk sharing with non-traded goods. For instance, the first column of results indicates that when the data are pooled, the estimated coefficient on $\beta_{1}$ is significant and negative, which is completely at odds with the theory. The panel data estimates, using both random effects and fixed effects, also confirm the findings that the data are seriously at odds with the theory. The instrumental variables estimates, presented in the two furthest columns on the right, provide weaker evidence of the rejection of the theory: namely, both estimates of $\beta_{1}$ are insignificantly different from zero, though one is still negative. Since the theory suggests that the coefficient should be positive, the evidence in the top panel of table indicates that the theory is unequivocally rejected by the data. ${ }^{15}$

To further investigate this wide empirical departure from the theory, in the bottom

\footnotetext{
${ }^{14}$ Theoretically speaking, the equation does not necessarily include the constant term $\beta_{0}$. The regression results reported in the paper are robust to the inclusion of the constant term.

${ }^{15}$ The instruments used in these regressions are the lagged value of the dependent and explanatory variables. We have mixed evidence for the strength of the instrumental variables. The first-stage $\mathrm{F}$ statistics are well above 20 in all estimates, indicating that the instruments are quite strong. However, the overidentifying restrictions are generally rejected, showing that these variables may not be valid instruments. Of course, this further indicates a departure from full risk sharing.
} 
panel of Table 4 we report the estimation results from the following specification:

$$
\Delta \tilde{c}_{i t}=\beta_{0}+\beta_{11} \cdot \Delta e_{i t}-\beta_{12} \cdot \Delta \tilde{p}_{i t}+\eta_{i t}
$$

Of course, specification (11) generalizes the theoretical specification (10) by expanding out the terms of the real exchange rate into the nominal exchange and the inflation differential. Note that we regain the earlier specification if $\beta_{11}=\beta_{12}$. The results in bottom panel of Table 4 suggest that, overall, both the coefficients on the exchange rate and the inflation differentials are statistically significant and of the wrong sign! For instance, this is demonstrated in the results for the panel regression, though the results using pooled data or instrumental variables panel data in a few instances show either a positive and statistically significant coefficient on $\beta_{11}$ or a negative and statistically significant coefficient on $\beta_{12}$. Overall, there are three instances in the bottom panel of Table 4 where the estimated coefficient on the bilateral movements in inflation have the correct sign and are statistically significant. In comparison, in one case is the coefficient on the nominal exchange rate, $\beta_{11}$, statistically significant and of the correct sign, though in three cases it is statistically significant and of the incorrect sign. ${ }^{16}$ Thus it would appear that the wide violation of complete risk sharing is mainly due to the nominal exchange rate movements.

The results in Tables 5 expand on the regressions in Table 4 by re-estimation specifications (10) and (11) over two distinct sub-samples of the data. To explore the idea that large movements in the nominal exchange rate are responsible for the wide violations of risk sharing, Table 5.A report estimates of these two specifications for time periods of small

\footnotetext{
${ }^{16}$ Note that for the IV panel data estimate using random effects, the coefficients on the two variables are statistically significant and of the theoretically predicted sign. However, the estimate coefficient implies a coefficient of risk aversion of over 17, which is likely to be implausibly high.
} 
movements in the nominal exchange rate, where a small movement is an annual change (in absolute value) of less than 10 percentage points. In contrast, the results in Table 5.B present the estimates for the sub-sample of large movements in the nominal exchange rate: that is, periods where the nominal exchange rate moved in excess of 10 percentage points (in absolute value) on an annual basis.

First consider the results in the top panel of Table 5.A, i.e. the 'quiet' exchange rate period, when we consider the estimates of expression (10) using bilateral data. Interestingly, the pooled estimate indicates the aforementioned problem that the estimates of $\beta_{1}$ are significant, though of the wrong sign. However, the panel estimates of $\beta_{1}$ all indicate a positive and statistically significant estimate for $\beta_{1}$. As well, the IV estimates using this sample of small exchange rate movements provide large, positive and statistically significant estimates that are consistent with a coefficient of relative risk aversion in the range of 3 to 4 . However, the results in Table 5.B where we estimate the specification using the sub-sample for large exchange rate movements continue to be disappointing. Indeed, the coefficients on $\beta_{1}$ are all statistically significant and all of the wrong sign!

Second, the bottom panels of Table 5.A and 5.B provide estimates of expression (11) for sub-samples of small and large nominal exchange rate movements, respectively. Generally, the results in the bottom panel of Table 5.A provide assurance that the theory performs better when exchange rate movements are small. Note that estimates of $\beta_{11}$ and $\beta_{12}$ are negatively and statistically significant for the pooling regression only and are positive and statistically significant in many other cases. When exchange rate movements are large, however, the coefficient of $\beta_{11}$ is always negative and statistically significant. Moreover, even the coefficient of $\beta_{12}$ is negative and statistically significant in three out of five cases. 
While the results in Tables 4 through 5 demonstrate the weakness of the theory and leave the impression that regimes with smaller movements in the nominal exchange rate are somewhat more consistent with the theory, one may conjecture that the Backus-Smith puzzle is due to partial risk sharing, i.e. only small portion of risk is shared across countries. Below, we investigate this issue. Without cross country risk sharing, each country's consumption growth should track her output growth, which can be represented as follows: ${ }^{17}$

$$
\Delta \tilde{c}_{i t}=\gamma_{0}+\gamma_{1} \cdot \Delta \tilde{y}_{i t}
$$

Now suppose that $\theta$ portion of consumption is realized by sharing risk across countries and the remaining $(1-\theta)$ portion is not, then the resulting consumption dynamics is obtained by summing up mulitiplication of $\theta$ to (10) and mulitiplication of $(1-\theta)$ to (12):

$$
\Delta \tilde{c}_{i t}=\alpha_{0}+\alpha_{1} \cdot \Delta \epsilon_{i t}+\alpha_{2} \cdot \Delta \tilde{y}_{i t}+\eta_{i t}
$$

where $\alpha_{0}=\theta \beta_{0}+(1-\theta) \gamma_{0}, \alpha_{1}=\theta \beta_{1}$ and $\alpha_{2}=(1-\theta) \gamma_{1}$. Equation (13) is generalization of equation (10) that allows for any degree of partial risk sharing depending on the value of $\theta$. Of course, with complete risk sharing, the coefficient on $\alpha_{2}$ should be zero $(\theta=1)$, as countries will consume out of joint resources rather than out of individual ones. The inclusion of the output growth ratio as an additional explanatory variable to estimate the portion of incomplete risk sharing has been used in many empirical tests of risk sharing (e.g. Crucini (1999), Hess and Shin (2000), etc...).

The top and the middle panels of Table 6 provide estimates of expression (13). Strikingly, whether the real exchange rate is included or not in the specification, the estimated

\footnotetext{
${ }^{17}$ We follow Crucini and Hess (2000) and Hess and Shin (2000) and assume that country consumption is affected by country income. Of course, if income follows a random walk, this specification indicates that country's consume out of their own permanent income.
} 
coefficient of $\Delta \tilde{y}_{i t}$ is large, positive and statistically significant. Indeed, the estimates of the coefficient are in the range of .5 to .8 , which is an extremely severe departure from complete international risk sharing. However, in the middle panel, we find that the Backus-Smith puzzle is considerablly weakened: namely that except for the pooling regression estimate, the coefficient of $\Delta \epsilon_{i t}$ is no longer significantly negative. It is not completely satisfactory, though, in the sense that the coefficient is not statistically positive, either.

Finally, in the bottom panel of Table 6, we decompose the real exchange rate in specification (13) into its nominal exchange rate and inflation components while also including the output ratio as an explanatory variable, namely:

$$
\tilde{c}_{i t}=\alpha_{0}+\alpha_{11} \cdot \Delta e_{i t}-\alpha_{12} \cdot \Delta \tilde{p}_{i t}+\alpha_{2} \cdot \Delta \tilde{y}_{i t}+\eta_{i t}
$$

As before, the results are no more promising for the theory. As demonstrated by the estimates for $\alpha_{2}$, the impact of country specific output on consumption is extremely large, significant and positive, whereas theory predicts that it should be zero. And again, the results suggest that the reason the coefficient of the real exchange rate growth is not positive is mainly due to the behavior of the nominal exchange rate. In four out of five instances, the coefficients of inflation differential are positive (of which three are statistically significant), while in three out of five instances the coefficients on the nominal exchange rate are negative (of which two are statistically significant).

Clearly, support for the theory of complete risk sharing across countries is nonexistent. And the departures from completeness are large and systematic. Our results suggest that the Backus-Smith puzzle should be closely related to existence of incomplete risk sharing. At the same time, however, our findings also stress the importance of the 
nominal exchange rate movements that generate the Backus-Smith puzzle. In the following section we examine some additional evidence within the United States. The value of this contrast between international and intranational data is that while the former is subject to exchange rate risk, the latter is not. See Asdrubali, Sorensen and Yosha (1996), Crucini (1999), Hess and Shin (1998) and the contributions to Hess and van Wincoop (2000) as well as others on the value of examining these differences.

\subsection{Some Intranational Comparisons}

In this sub-section, we explore some intranational evidence on risk sharing. Again, the benefit to juxtaposing international and intranational data are that only the former is exposed to exchange rate risk. The intranational data are from Del Negro (2002), who provides consumption (as measured by retail sales), output (as measured by Gross State Product) and price data (based on the CPI for cities) for the 50 United States. Data such as this is standard in the Intranational Macroeconomics literature cited above.

Table 7 provides some useful summary evidence of the co-movement of variables within and between countries. The first column of data reports the pooled cross correlation for output growth across countries as well as the pooled cross correlation for consumption growth across countries. According to the theory as originated by Backus, Kehoe and Kydland (1992), countries that share risk should have consumption paths that are more correlated than output paths. As is seen from the results in Table 2, however, this is clearly violated in the international data, with the cross correlation of consumption being almost one-third smaller than that for output. Moving to the second column, however, the intranational data for the U.S. demonstrates that the cross correlations for both consumption and output are much higher. Nevertheless, the cross correlation of consumption is about half as large as 
that for output, a serious violation of the theory which predicts that the latter should be larger than the former.

Now we examine if the Backus-Smith puzzle remains in intranational data. The first set of results are estimates of empirical specification (10) that are provided in Table 8. Of course, since the bilateral nominal exchange rate across U.S. states is one, the measure of the bilateral real exchange rate is just $\epsilon_{i t} \equiv-\Delta p_{i t}+\Delta p_{j t} \equiv-\Delta \tilde{p}_{i t}$. The estimation results from the pooling and panel data estimates are quite encouraging, especially vis a vis the international evidence provided above. The empirical estimates are positive and statistically significant, with an implied value of the coefficient of relative risk aversion equal to approximately 2 to 4 . Interestingly, the IV panel estimates are positive and fairly large, on the order of about 2 .

Finally, the results for empirical specification (13) that allows for incomplete risk sharing are presented in Table 9. As before, in an environment of incomplete risk sharing, controlling for country specific output movements is appropriate. The results indicate that idiosyncratic movements in bilateral country output growth are significant predictors of bilateral consumption growth rates. As such, this is a rejection of the theory of complete risk sharing across countries. ${ }^{18}$ Nevertheless, the estimated coefficients on output movements are remarkably smaller for intranational data as compared to international data. As well, the estimate coefficients on real exchange rates, $\alpha_{1}$ are consistent with the theory and provide reasonable estimates of the coefficient of risk aversion. The results for the IV Panel estimates are somewhat unusual by providing an estimated negative coefficient on $\beta_{2}$.

Our evidence based on the intranational data also suggests that if the nominal ex-

\footnotetext{
${ }^{18}$ See Del Negro (2002) for a similar assessment of the intranational versus international data.
} 
change rate is constant, the Backus-Smith puzzle disappears.

\section{Conclusion}

Backus, Kehoe and Kydland (BKK 1992) showed that if international capital markets are complete, consumption growth correlations across countries should be higher than their corresponding output growth correlations. In stark contrast to the theory, however, in actual data the consumption growth correlation is lower than the output growth correlation. By assuming trade imperfections due to non-traded goods, Backus and Smith (1993) showed that there is an additional impediment that works to lower the consumption growth correlation. While Backus and Smith's argument was successful in lowering the consumption growth correlation, it contributed to generating another puzzle because the data forcefully showed that consumption growth is negatively correlated with the real exchange rate, which is a violation of the theory.

In this paper, by decomposing the real exchange rate growth of the OECD countries into the nominal exchange rate growth and the inflation differential, we find that nominal exchange rate movements are the main source of the Backus-Smith puzzle. We find that the nominal exchange rate moves counter-cyclically with consumption movements, which is a violation of the risk sharing theory with non-traded goods. In contrast, bilateral inflation differentials are negatively correlated with bilateral consumption movements. The latter finding is in accordance with the theory.

The evidence that the nominal exchange rate fluctuations contribute to the BackusSmith puzzle is corroborated by three additional experiments. First, we divide the sample into sub-samples with large exchange rate changes and another with small exchange rate 
changes, and find that the ill behavior of the real exchange rate is present primarily when nominal exchange changes are large. Second, when we modify the model to allows for partial risk sharing, the Backus-Smith puzzle becomes less severe, though it is still present. Again, this puzzle is due to the fact that nominal exchange rate movements are still countercyclical even after we introduce the possibility of partial risk sharing. In contrast, the negative of inflation differential is strongly procyclical contributing to less severe violation of the theory. Third, using data for 50 U.S. states, where the nominal exchange rate is constant, we find that the Backus-Smith puzzle disappears even though risk sharing is still imperfect.

Overall, we believe that theory still faces two strong challenges. First, to explain why international and intranational risk sharing is still incomplete. Second, to account for why nominal exchange rate movements compound the theoretical violations of risk sharing rather than ameliorate them. 


\section{References}

Asdrubali, Pierfederico, Sorensen, Bent E. and Yosha, Oved. "Channels of Interstate Risksharing: US 1963-1990," Quarterly Journal of Economics, November 1996, 111, 10811110.

Backus, David K., Kehoe, Patrick J. and Kydland, Finn E. "International Real Business Cycles," Journal of Political Economy, March 1992, 84, 84-103.

Backus, David K. and Gregor W. Smith "Consumption and Real Exchange Rates in Dynamic Economies with Non-traded Goods," Journal of International Economics, November 1993, 35, 297-316.

Canova, Fabio and Ravn, Morten O. "International Consumption Risk Sharing" International Economic Review, August 1996, 37, 573-601.

Crucini, Mario J. "On International and National Dimensions of Risk Sharing," Review of Economics and Statistics February 1999, 81, No.1, 73-84.

Crucini, Mario J. and Gregory D. Hess "Intranational and International Risk Sharing," in Gregory D. Hess and Eric van Wincoop, eds., Intranational Macroeconomics 2000, Cambridge University Press.

Del Negro, Marco. "Asymmetric Shocks Among U.S. States?" Journal of International Economics, March 2002, 56, 273-297.

Engel, Charles. "Comments on Obstfeld and Rogoff's "The Six Major Puzzles in International Macroeconomics: Is There A Common Cause?"' NBER Macroeconomics Annual 2000, in Ben Bernake and Kenneth Rogoff eds., February 2001, 15 403-11.

Feldstein, Martin and Horioka, Charles "Domestic Savings and International Capital Flows," Economic Journal, June 1980, 90, 314-329. 
Hess, Gregory D. and Shin, Kwanho. "Risk Sharing Within and Across Regions and Industries," Journal of Monetary Economics, August 2000, 45), 533-560.

Hess, Gregory D. and Shin, Kwanho. "Intranational Business Cycles in the United States," Journal of International Economics, April 1998, 44, 289-314.

Kollman, Robert. "Consumption, Real Exchange Rates, and the Structure of International Capital Markets," Journal of International Money and Finance, April 1995, 14, 191-211.

Lewis, Karen K. "What can Explain the Apparent Lack of International Consumption Risk Sharing," Journal of Political Economy, April 1996, 104, 267-97.

Mace, Barbara J. "Full Insurance in the Presence of Aggregate Uncertainty," Journal of Political Economy, October 1991, 99, 928-56.

Obstfeld, Maurice. "How Integrated are World Capital Markets? Some New Tests," in Guillermo Calvo, Ronald Findlay, Pentti Kouri, and Jorge Braga de Macedo eds. Debt, Stabilization and Development: Essays in Memory of Carlos Diaz-Alejandro, Oxford, U.K.: Basil Blackwell

Obstfeld, Maurice. "Are Industrial-Country Consumption Risks Globally Diversified," in Real business cycles, real exchange rates and actual policies, in Capital mobility: the impact on consumption, investment and growth, eds. Leonardo Leiderman and Assaf Razin, 1994, Cambridge University Press, Cambridge, U.K.

Obstfeld, Maurice, and Rogoff, Kenneth, "The Six Major Puzzles in International Macroeconomics: Is There A Common Cause?" NBER Macroeconomics Annual 2000, in Ben Bernake and Kenneth Rogoff eds., February 2001, 339-90.

Ravn, Morten O. "Consumption Dynamics and Real Exchange Rates" April 2001, mimeo. Sorensen, Bent E. and Yosha, Oved. "Income and Consumption Smoothing Among U.S. 
States: Regions or Clubs?" June 1996, mimeo. 
Table 1: Country Statistics (OECD Countries), 1969-2000

\begin{tabular}{|c|c|c|c|c|c|}
\hline CNTRY & $\Delta c$ & $\Delta y$ & $\Delta p$ & $\Delta e$ & $\Delta \epsilon$ \\
\hline$\overline{\text { AUS }}$ & $.024(.032)$ & $.018(.018)$ & $.065(.059)$ & .021(.082) & $.001(.097)$ \\
\hline AUT & $.033(.041)$ & $.025(.018)$ & $.039(.023)$ & $-.018(.109)$ & $-.012(.106)$ \\
\hline BEL & $.024(.019)$ & $.024(.019)$ & $.043(.030)$ & $-.004(.116)$ & $-.003(.111)$ \\
\hline CAN & $.018(.021)$ & $.020(.022)$ & $.050(.031)$ & $.010(.039)$ & $.005(.040)$ \\
\hline CHE & $.011(.015)$ & $.010(.022)$ & $.034(.026)$ & $-.031(.119)$ & $-.020(.120)$ \\
\hline DNK & $.022(.055)$ & $.017(.019)$ & $.060(.036)$ & $.002(.108)$ & $-.013(.107)$ \\
\hline ESP & $.023(.046)$ & $.023(.029)$ & $.089(.066)$ & $.031(.117)$ & $-.014(.127)$ \\
\hline FIN & $.024(.027)$ & $.027(.029)$ & $.065(.043)$ & $.014(.101)$ & $-.006(.101)$ \\
\hline FRA & $.026(.039)$ & $.021(.016)$ & $.057(.040)$ & $.010(.114)$ & $-.002(.108)$ \\
\hline GBR & $.024(.019)$ & $.020(.020)$ & $.073(.050)$ & $.015(.088)$ & $-.013(.090)$ \\
\hline GER & $.029(.039)$ & $.020(.016)$ & $.032(.020)$ & $-.018(.112)$ & $-.005(.110)$ \\
\hline GRC & $.029(.029)$ & $.021(.035)$ & $.127(.061)$ & $.081(.093)$ & $-.002(.089)$ \\
\hline IRL & $.033(.043)$ & $.041(.030)$ & $.078(.055)$ & $.023(.103)$ & $-.010(.089)$ \\
\hline ISL & $.038(.066)$ & $.028(.034)$ & $.194(.171)$ & $.145(.188)$ & $-.005(.103)$ \\
\hline ITA & $.026(.051)$ & .023 (.019) & $.090(.055)$ & $.039(.113)$ & $-.006(.105)$ \\
\hline JPN & $.031(.027)$ & $.028(.023)$ & $.038(.043)$ & $-.039(.108)$ & $-.032(.110)$ \\
\hline KOR & $.047(.040)$ & $.058(.038)$ & $.109(.076)$ & $.044(.105)$ & $-.020(.099)$ \\
\hline LUX & $.033(.036)$ & $.032(.033)$ & $.042(.031)$ & $-.004(.116)$ & $-.001(.104)$ \\
\hline MEX & $.014(.040)$ & $.016(.038)$ & $.262(.211)$ & $.214(.289)$ & $-.003(.149)$ \\
\hline NLD & $.026(.043)$ & $.021(.016)$ & $.040(.028)$ & $-.013(.110)$ & $-.008(.110)$ \\
\hline NOR & $.023(.024)$ & $.029(.018)$ & $.061(.030)$ & $.007(.082)$ & $-.009(.083)$ \\
\hline NZL & $.008(.026)$ & $.010(.027)$ & $.080(.078)$ & $.029(.098)$ & $-.006(.120)$ \\
\hline PRT & $.028(.051)$ & $.032(.037)$ & $.119(.087)$ & $.065(.121)$ & $-.009(.100)$ \\
\hline SWE & $.013(.075)$ & $.017(.020)$ & $.066(.036)$ & $.018(.104)$ & $-.002(.101)$ \\
\hline TUR & $.016(.056)$ & $.022(.044)$ & $.394(.187)$ & $.360(.238)$ & $.010(.155)$ \\
\hline USA & $.023(.018)$ & $.021(.021)$ & $.045(.024)$ & $0()$. & $0()$. \\
\hline$\overline{\mathrm{AVE}}$ & $.025(.041)$ & $.024(.028)$ & $.091(.111)$ & $.038(.151)$ & $-.007(.1$ \\
\hline
\end{tabular}

Notes: Columns report the mean and standard deviations (in parentheses) of the series. All data (except where noted) are from Penn-World data set, 1969-2000, including country code mnemonics. The nominal exchange rate is defined as the number of units of the domestic currency per unit of the U.S. dollar. The price series used is the CPI index that is derived by deviding nominal consumption by real consumption. AVE is the Average of the entire data of 832 observations. CNTRY refers to county. $\Delta c$ and $\Delta y$ are annual per capita growth of real consumption and real GDP (log changes), respectively, from the national accounts. $\Delta p$ is the annual inflation rate measured by the CPI index and $\Delta e$ is the annual growth rate of the nominal exchange rate. $\Delta \epsilon$ is the annual growth rates of the real exchange rate (log changes). Note that $\Delta \epsilon=\Delta e+\Delta p^{f}-\Delta p^{d}$ where $f$ refers to the foreign country and $d$ refers to the domestic country. 
Table 2: Bilateral Volatility Statistics (OECD Countries), 1969-2000

\begin{tabular}{lcccccccc}
\hline CNTRY & $\Delta \tilde{c}$ & $\Delta \tilde{y}$ & $\Delta \tilde{p}$ & $\Delta e$ & $\Delta \epsilon$ & $\rho(\Delta \tilde{p}, \Delta e)$ & $\rho(\Delta \tilde{p}, \Delta \epsilon)$ & $\rho(\Delta e, \Delta \epsilon)$ \\
\hline AUS & .051 & .031 & .117 & .153 & .110 & .713 & .101 & .714 \\
AUT & .053 & .030 & .110 & .140 & .086 & .795 & .079 & .640 \\
BEL & .042 & .028 & .110 & .139 & .088 & .787 & .068 & .639 \\
CAN & .044 & .030 & .108 & .153 & .110 & .702 & .045 & .720 \\
CHE & .041 & .031 & .112 & .147 & .098 & .761 & .055 & .665 \\
DNK & .064 & .030 & .110 & .138 & .084 & .796 & .071 & .630 \\
ESP & .057 & .035 & .117 & .142 & .093 & .725 & -.005 & .629 \\
FIN & .046 & .035 & .110 & .143 & .096 & .774 & .073 & .658 \\
FRA & .054 & .028 & .108 & .140 & .089 & .791 & .093 & .655 \\
GBR & .043 & .030 & .111 & .144 & .098 & .760 & .025 & .644 \\
GER & .055 & .028 & .112 & .142 & .090 & .791 & .066 & .632 \\
GRC & .046 & .039 & .115 & .137 & .085 & .804 & .008 & .563 \\
IRL & .056 & .039 & .114 & .141 & .086 & .799 & .061 & .608 \\
ISL & .074 & .039 & .175 & .200 & .100 & .884 & .233 & .617 \\
ITA & .059 & .029 & .110 & .145 & .093 & .780 & .089 & .667 \\
JPN & .047 & .033 & .113 & .162 & .117 & .689 & .042 & .734 \\
KOR & .055 & .045 & .123 & .176 & .125 & .689 & .046 & .735 \\
LUX & .051 & .039 & .110 & .139 & .089 & .800 & .081 & .591 \\
MEX & .056 & .045 & .228 & .325 & .185 & .827 & .262 & .750 \\
NLD & .057 & .028 & .112 & .140 & .087 & .785 & .036 & .622 \\
NOR & .049 & .033 & .110 & .133 & .083 & .808 & .029 & .548 \\
NZL & .047 & .037 & .114 & .148 & .101 & .700 & -.017 & .639 \\
PRT & .062 & .039 & .124 & .148 & .089 & .791 & .127 & .638 \\
SWE & .084 & .031 & .109 & .140 & .089 & .789 & .085 & .651 \\
TUR & .069 & .052 & .219 & .251 & .141 & .782 & -.056 & .535 \\
USA & .043 & .030 & .109 & .152 & .108 & .716 & .057 & .717 \\
\hline Ave & .056 & .036 & .152 & .185 & .103 & .830 & .084 & .595
\end{tabular}

Notes: See Table 1. For country d (domestic) and f (foreign), $\Delta \tilde{x} \equiv \Delta \log \left(x^{d}\right)-\Delta \log \left(x^{f}\right)$ for $x=c, y, p$ : namely, it is the difference between country $d^{\prime} s$ and $f^{\prime} s$ growth rate of variable $\mathrm{x}$. The nominal exchange rate is defined as the number of units of the domestic currency per unit of foreign currency. Volatility is measured as the pooled standard deviation of country d's bilateral data with all other countries. $\rho(x, y)$ is country d's pooled correlation of variables $\mathrm{x}$ and $\mathrm{y}$ using its bilateral data with all other countries. 
Table 3: Correlation with Consumption Ratio

\begin{tabular}{l|ccc}
\hline CNTRY & $\rho(\Delta \tilde{c}, \Delta \epsilon)$ & $\rho(\Delta \tilde{c}, \Delta e)$ & $\rho(\Delta \tilde{c},-\Delta \tilde{p})$ \\
\hline AUS & -.046 & -.244 & .277 \\
AUT & .006 & -.114 & .149 \\
BEL & -.052 & -.140 & .137 \\
CAN & -.063 & -.154 & .154 \\
CHE & -.012 & -.132 & .163 \\
DNK & -.004 & -.127 & .156 \\
ESP & .078 & -.161 & .261 \\
FIN & -.218 & -.247 & .142 \\
FRA & -.113 & -.135 & .084 \\
GBR & -.060 & -.192 & .197 \\
GER & -.056 & -.109 & .094 \\
GRC & -.065 & -.235 & .235 \\
IRL & -.004 & -.162 & .198 \\
ISL & -.250 & -.310 & .221 \\
ITA & -.093 & -.153 & .124 \\
JPN & .018 & -.107 & .172 \\
KOR & -.367 & -.393 & .180 \\
LUX & -.115 & -.164 & .120 \\
MEX & -.548 & -.550 & .334 \\
NLD & -.121 & -.178 & .128 \\
NOR & -.066 & -.182 & .174 \\
NZL & -.112 & -.238 & .186 \\
PRT & -.120 & -.300 & .270 \\
SWE & .184 & .054 & .076 \\
TUR & .113 & -.139 & .240 \\
USA & -.205 & -.249 & .148 \\
\hline AVE & -.098 & -.174 & .163 \\
\hline
\end{tabular}

Notes: See Tables 1 and 2. $\rho(x, y)$ is country d's pooled correlation of variables $\mathrm{x}$ and y using its bilateral data with all other countries. 
Table 4: Real Exchange Decomposition Regression

\begin{tabular}{|c|c|c|c|c|c|}
\hline \multicolumn{6}{|c|}{$\Delta \tilde{c}_{i t}=\beta_{0}+\beta_{1} \cdot \Delta \epsilon_{i t}+\eta_{i t}$} \\
\hline & \multirow[b]{2}{*}{ Pooling } & \multicolumn{2}{|c|}{ Panel } & \multicolumn{2}{|c|}{ IV Panel } \\
\hline & & Random Effects & Fixed Effects & Random Effects & Fixed Effects \\
\hline \multirow[t]{2}{*}{$\overline{\Delta \epsilon}$} & $-.073^{* *}$ & $-.052^{* *}$ & $-.049^{* *}$ & .000 & -.024 \\
\hline & {$[.003]$} & {$[.005]$} & {$[.005]$} & {$[.025]$} & {$[.022]$} \\
\hline \multirow[t]{2}{*}{$R^{2}$} & .04 & .01 & .01 & .02 & .03 \\
\hline & \multicolumn{5}{|c|}{$\Delta \tilde{c}_{i t}=\beta_{0}+\beta_{11} \cdot \Delta e_{i t}-\beta_{12} \cdot \Delta p_{i t}+\eta_{i t}$} \\
\hline \multirow[t]{2}{*}{$\overline{\Delta e}$} & $-.073^{* *}$ & $-.051^{* *}$ & $-.053^{* *}$ & $.057^{*}$ & .036 \\
\hline & {$[.003]$} & {$[.005]$} & {$[.005]$} & {$[.024]$} & {$[.021]$} \\
\hline \multirow[t]{2}{*}{$-\Delta \tilde{p}$} & $-.023^{* *}$ & $.024^{* *}$ & $.068^{* *}$ & $.058^{*}$ & -.001 \\
\hline & {$[.004]$} & {$[.007]$} & {$[.007]$} & {$[.024]$} & {$[.021]$} \\
\hline$R^{2}$ & .08 & .04 & .06 & .01 & .04 \\
\hline OBS & 10050 & 10050 & 10050 & 8425 & 8425 \\
\hline
\end{tabular}

Notes: See Tables 1-3. Estimated standard errors are in square brackets. $R^{2}$ is the standard r-squared from the regression. OBS is the number of observations. Pooling regressions also include a constant (not shown). Instruments include the lagged value of the dependent variable and the explanatory variables. 
Table 5: Real Exchange Regression: Small vs. Large Exchange Movements

\section{A. Small Exchange Movements}

\begin{tabular}{|c|c|c|c|c|c|}
\hline \multicolumn{6}{|c|}{$\Delta \tilde{c}_{i t}=\beta_{0}+\beta_{1} \cdot \Delta \epsilon_{i t}+\eta_{i t}$} \\
\hline & \multirow[b]{2}{*}{ Pooling } & \multicolumn{2}{|c|}{ Panel } & \multicolumn{2}{|c|}{ IV Panel } \\
\hline & & Random Effects & Fixed Effects & Random Effects & Fixed Effects \\
\hline \multirow[t]{2}{*}{$\overline{\Delta \epsilon}$} & $-.034^{* *}$ & $.088^{* *}$ & $.102^{* *}$ & $.252^{* *}$ & $.272^{* *}$ \\
\hline & {$[.006]$} & {$[.010]$} & {$[.010]$} & {$[.063]$} & {$[.070]$} \\
\hline \multirow[t]{2}{*}{$R^{2}$} & .01 & .02 & .02 & .01 & .01 \\
\hline & & $\Delta \tilde{c}_{i t}=\beta_{0}+$ & $\beta_{11} \cdot \Delta e_{i t}-\beta_{12}$ & $\Delta p_{i t}+\eta_{i t}$ & \\
\hline \multirow[t]{2}{*}{$\overline{\Delta e}$} & $-.040^{* *}$ & .011 & -.002 & $.592^{* *}$ & $464^{* *}$ \\
\hline & {$[.008]$} & {$[.014]$} & {$[.014]$} & {$[.142]$} & {$[.143]$} \\
\hline \multirow[t]{2}{*}{$-\Delta \tilde{p}$} & $-.030^{* *}$ & $139^{* *}$ & $182^{* *}$ & .025 & .056 \\
\hline & {$[.007]$} & {$[.012]$} & {$[.013]$} & {$[.040]$} & {$[.044]$} \\
\hline$R^{2}$ & .01 & .03 & .03 & .01 & .01 \\
\hline OBS & 6581 & 6581 & 6581 & 5261 & 5261 \\
\hline
\end{tabular}

Notes: See Table 4. The data are censored so that observations where the annual log change in the nominal exchange rate exceeds 10 percent are removed.

\section{B. Large Exchange Movements}

\begin{tabular}{|c|c|c|c|c|c|}
\hline & & \multicolumn{4}{|c|}{$\Delta \tilde{c}_{i t}=\beta_{0}+\beta_{1} \cdot \Delta \epsilon_{i t}+\eta_{i t}$} \\
\hline & Pooling & Random Effects & Fixed Effects & Random Effects & Fixed Effects \\
\hline$\overline{\Delta \epsilon}$ & $\begin{array}{c}.091^{* *} \\
{[.005]}\end{array}$ & $\begin{array}{c}. .083^{* *} \\
{[.007]}\end{array}$ & $\begin{array}{c}.082^{* *} \\
{[.007]}\end{array}$ & $\begin{array}{c}.124^{* *} \\
{[.024]}\end{array}$ & $\begin{array}{c}-.122^{* *} \\
{[.023]}\end{array}$ \\
\hline$R^{2}$ & .09 & .04 & .04 & .04 & .05 \\
\hline \multicolumn{6}{|c|}{$\Delta \tilde{c}_{i t}=\beta_{0}+\beta_{11} \cdot \Delta e_{i t}-\beta_{12} \cdot \Delta p_{i t}+\eta_{i t}$} \\
\hline$\overline{\Delta e}$ & $\begin{array}{c}.082^{* *} \\
{[.005]}\end{array}$ & $\begin{array}{c}.079^{* *} \\
{[.007]}\end{array}$ & $\begin{array}{c}.082^{* *} \\
{[.007]}\end{array}$ & $\begin{array}{c}.064^{* *} \\
{[.022]}\end{array}$ & $\begin{array}{c}.060^{* *} \\
{[.022]}\end{array}$ \\
\hline$-\Delta \tilde{p}$ & $\begin{array}{c}-.035 * * \\
{[.006]}\end{array}$ & $\begin{array}{l}-.006 \\
{[.009]}\end{array}$ & $\begin{array}{c}.019 \\
{[.010]}\end{array}$ & $\begin{array}{c}-.054^{*} \\
{[.023]}\end{array}$ & $\begin{array}{c}-.108^{* *} \\
{[.026]}\end{array}$ \\
\hline$R^{2}$ & .13 & .09 & .08 & .08 & .07 \\
\hline OBS & 3469 & 3469 & 3469 & 3164 & 3164 \\
\hline
\end{tabular}

Notes: See Table 4. The data are censored so that observations where the annual log change in the nominal exchange rate less than or equal to 10 percent are removed. 
Table 6: Output Ratio Estimation

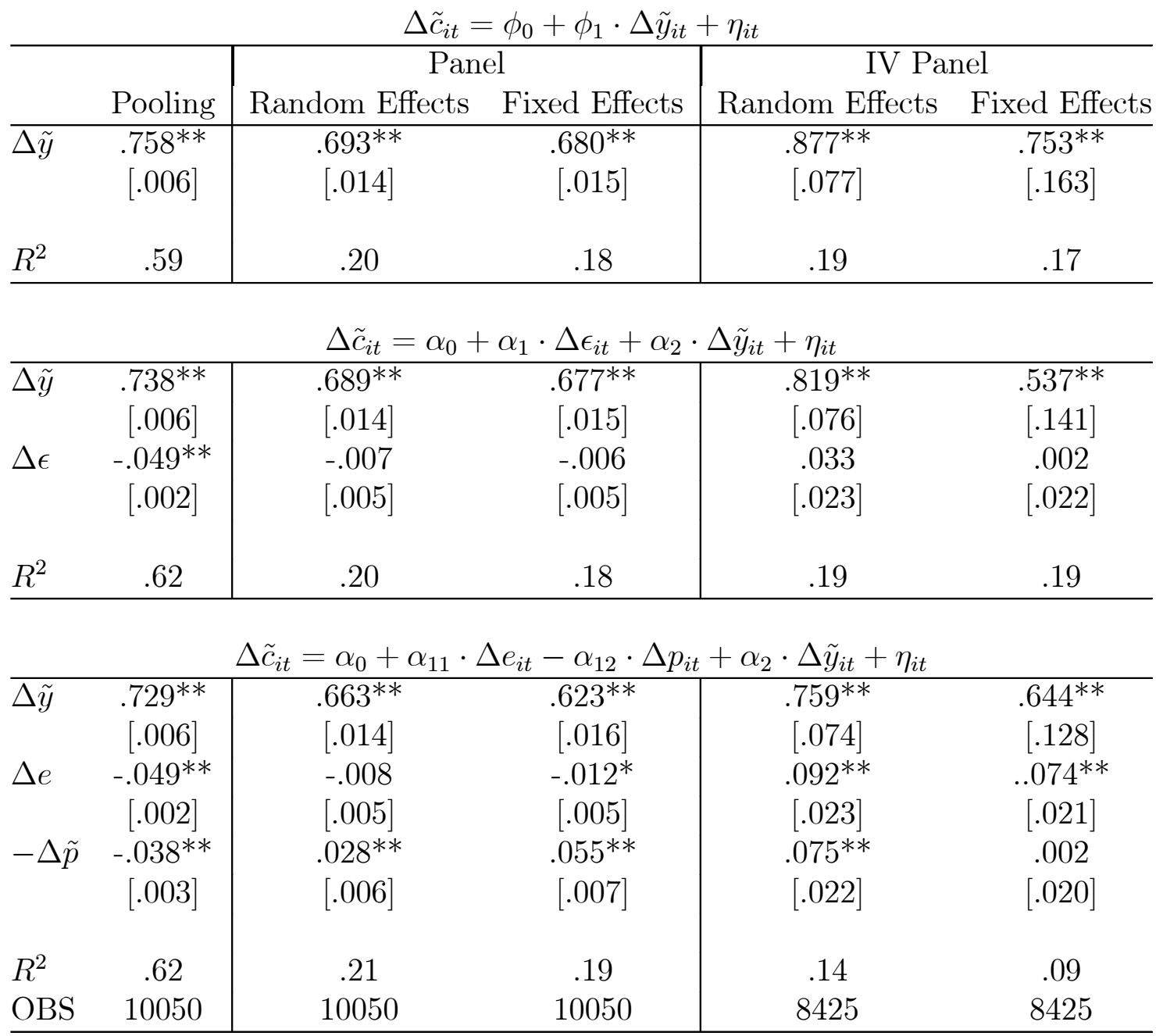

Notes: See Table 4.

Table 7: Consumption Correlation Puzzle

\begin{tabular}{l|cc} 
& & \\
\hline & International & Intranational \\
\hline$\rho\left(y_{i t}, y_{j t}\right)$ & .174 & .392 \\
$\rho\left(c_{i t}, c_{j t}\right)$ & .062 & .183 \\
\hline OBS & 10,050 & 25725 \\
\hline
\end{tabular}

Notes: See Tables 1 and 3. $\rho(x, y)$ is the pooled cross correlation of variables $\mathrm{x}$ and $\mathrm{y}$ using bilateral data for all countries or U.S. states. Intranational data are for U.S. States, 1969-1990. GSP data and Consumption (i.e. Retail Sales ) data are from the Bureau of Economic Analysis. State level CPI indices are from Del Negro (2002). 
Table 8: Real Exchange Regression: US States (1969-1990)

\begin{tabular}{cc|cc|cc}
\multicolumn{6}{c}{$\Delta \tilde{c}_{i t}=\beta_{0}+\beta_{1} \cdot \Delta \epsilon_{i t}+\eta_{i t}$} \\
\hline & & \multicolumn{3}{|c}{ Panel } & \multicolumn{2}{c}{ IV Panel } \\
& Pooling & Random Effects & Fixed Effects & Random Effects & Fixed Effects \\
\hline$\Delta \epsilon$ & $.508^{* *}$ & $.246^{* *}$ & $.268^{* *}$ & $2.181^{* *}$ & $1.855^{* *}$ \\
& {$[.028]$} & {$[.033]$} & {$[.035]$} & {$[.242]$} & {$[.276]$} \\
& & & & & .003 \\
$R^{2}$ & .01 & .002 & .003 & .003 & 19600 \\
OBS & 25725 & 25725 & 25725 & 19600 & \\
\hline
\end{tabular}

Notes: See Tables 5 and 7. Note that for US State data, $\Delta \epsilon_{i t}=-\Delta \tilde{p}_{i t}$.

Table 9: Output Ratio Estimation: US States (1969-1990)

\begin{tabular}{|c|c|c|c|c|c|}
\hline \multicolumn{6}{|c|}{$\frac{\Delta \tilde{c}_{i t}=\alpha_{0}+\alpha_{1} \cdot \Delta \epsilon_{i t}+\alpha_{2} \cdot \Delta \tilde{y}_{i t}+\eta_{i}}{\text { Panel }}$} \\
\hline & Pooling & Random Effects & Fixed Effects & Random Effects & Fixed Effects \\
\hline \multirow[t]{2}{*}{$\overline{\Delta \tilde{y}}$} & $174^{* *}$ & $131^{* *}$ & $121^{* *}$ & $-.784^{* *}$ & $-.963 * *$ \\
\hline & {$[.006]$} & {$[.007]$} & {$[.007]$} & {$[.109]$} & {$[.095]$} \\
\hline \multirow[t]{2}{*}{$R^{2}$} & .03 & .01 & .01 & .02 & .02 \\
\hline & & $\Delta \tilde{c}_{i t}=\alpha_{0}+\alpha_{11}$ & $\Delta e_{i t}-\alpha_{12} \cdot \Delta p_{t}$ & $+\alpha_{2} \cdot \Delta \tilde{y}_{i t}+\eta_{i t}$ & \\
\hline \multirow[t]{2}{*}{$\overline{\Delta \tilde{y}}$} & $.167^{* *}$ & $.127^{* *}$ & $.117^{* *}$ & $.292^{* *}$ & $-.185^{* *}$ \\
\hline & {$[.006]$} & {$[.007]$} & {$[.007]$} & {$[.067]$} & {$[.069]$} \\
\hline \multirow[t]{2}{*}{$\Delta \epsilon$} & $453^{* *}$ & $192^{* *}$ & $220^{* *}$ & $.380^{*}$ & $.872^{* *}$ \\
\hline & {$[.027]$} & {$[.033]$} & {$[.034]$} & {$[.191]$} & {$[.214]$} \\
\hline$R^{2}$ & .04 & .01 & .01 & .03 & .01 \\
\hline OBS & 25725 & 25725 & 25725 & 19600 & 19600 \\
\hline
\end{tabular}

Notes: See Table 8. 